\title{
Reflections on Local Specialties and Gastronomic Tourism
}

\author{
Yuan Su \\ Management School, Jinan University, Guangzhou, China \\ Email: yuansu1989@163.com
}

Received 13 January 2015; accepted 30 January 2015; published 4 February 2015

Copyright (C) 2015 by author and Scientific Research Publishing Inc.

This work is licensed under the Creative Commons Attribution International License (CC BY). http://creativecommons.org/licenses/by/4.0/

c) (i) Open Access

\begin{abstract}
Local food as an essential part of tourist experience has aroused many scholars' attention, and accumulated a wealth of research results. In 2000, scholars who were inspired by the theme of endless food festivals and other food-related activities, put forward gastronomic tourism. It has now become an important branch of special-interest tourism. From only one of the six elements of tourism attractions to gastronomic tourism, the relationship of local food and tourism has become increasingly close. Giving the scarcity of research on tourist food preferences and motivations of gastronomic tourism, this paper aims to advance the understanding of gastronomic tourism by using in-depth interviews. The study explores motivational factors for local food and tourist food preferences when traveling in different regions of China. Its findings indicate that most Chinese tourists treat local food as the extension of the daily dietary experience. Some recommendations are therefore offered in the study with the hope of better meeting the diverse dietary needs of tourists.
\end{abstract}

\section{Keywords}

Local Food, Tourist Food Preferences, Dining Motivation, Chinese Food Culture, Gastronomic Tourism

\section{Introduction}

Previous research on the relationship between food and tourists started relatively late; the study began in the late twentieth century. In 2000, the first international conference on local food and tourism was held in Cyprus. Most of the articles presented at the conference agreed that local food was a unique attraction at the destination. Since the beginning of the 21st century, scholars have paid more and more attention to gastronomic tourism. Gastronomic tourism has become one of the most interesting and fastest-growing research topics (Kim, Kim \& Goh, 
2011). Hjalager and Richards (2002: pp. 3-20) stated that tasting local food was often considered as both cultural activity and entertainment, which was also a necessary part of tourism experience [2]. In addition, tasting local foods has become an important way to enjoy the local culture (Long, 2004). However, Cohen and Avieli (2004) mentioned that local foods might be an attraction or impediment to tourist experience. In the paper, they pointed out that local foods could be accepted by mass tourists only through its adaptation to tourists' taste. Fischler (1988) pointed out two natural tendencies that were diametrically opposed to each other in the acceptance of novel food: "neophobia” and "neophobic". He explained that people who had the former tendency did not like to try new or unfamiliar food. On the contrary, people who were neophobic were fond of trying novel food. In this case, the tendency of existing "food neophobia” brings challenges to destination market and hospitality industry as regards how to present the local food as an attraction at the risk of potential impediment (Okumus, Okumus, \& McKercher, 2007). To make local food an important attraction requires in-depth understanding of food culture and tourists' food preferences. This paper takes Chinese tourists in different regions as examples to study Chinese tourists' food preferences and dining motivations in different regions. And it provides some guidance to local food market development of the destination.

\section{Food Consumption and Tourist Food Preferences}

\subsection{Local Food and Food Consumption}

Enteleca Research and Consultancy (2000) defined local food as food and beverages produced in the local area. Local food at a destination can bring tourists physical, cultural, social and prestige experience (Fields, 2002: pp. 36-50). From the perspective of tourist experience, the experience of local food consumption can be seen as both supporting experience and peak experience for tourists. For most tourists, the supporting experience is seen as an extension of their daily diet during journey. When tourists' visit to a place is motivated by the search of novel and unusual food experience different from what they eat on daily basis, local food consumption can turn to be the peak consumer experience (Quan Shuai \& Wang Ning, 2004).

\subsection{Tourist Food Preferences}

Many researchers have tried to explore the factors that affect food preferences. Among numerous factors, cultural influences on food preferences play a decisive role (Longue, 1991). Culture is a major determinant of what and how people eat (Rozin, 1996). It also defines whether food is acceptable or not, and delicious or not within a particular cultural group (Rozin \& Rozin, 1981). Due to cultural differences, what is considered as delicious food in one culture might be considered as unacceptable food in another. For example, Japanese love raw fish, but Chinese mostly regard it as unhealthy food.

The impacts of culture on tourist food preferences are frequently seen in research literature. Cohen and Avieli (2004) mentioned that the majority of Asian tourists were unwilling to try new food, while Westerners were comparatively more willing to try exotic food (Kim, Kim, \& Goh, 2011). Chang et al. (2010) took Chinese tourists' trip to Australia as an example, finding out that Chinese tourists were fond of both familiar flavor and "acceptable” unfamiliar local food.

\subsection{Chinese Food Culture}

Chinese food culture is famous for its diversity and adaption (Chang, 1977). Northeners in China prefer noodles, but southerners like to eat rice. A typical meal in Chinese culture consists of the principal food (rice and food made from wheat flour) and dishes (vegetables and meat) (Chang, 1977). The saying "South sweet and North salty, East spicy and West acid” 南甜北咸东辣西酸 has been known to us. Chinese eating preferences and habits are related to geographical environment to a certain extent (Chun Juan, 2003). This reflects that Chinese food culture varies from region to region.

\section{The Motivational Factors for Gastronomic Tourism}

\subsection{The Motivational Factors for Local Food Consumption}

Motivational factors for food consumption can significantly affect tourists' choices and behaviors. Fields (2002) demonstrated that motivation for local food consumption could be attributed to four key dimensions: physics, 
culture, communication, and reputation. The physical dimension refers to the relaxation of mind and body, the cultural dimension means the exploration of local culture and knowledge, the social dimension includes having a meal with relatives and friends to strengthen relationship and enhance connections. Reputation and status dimension covers self-esteem, recognition and desire to attract other people's attention by enjoying exotic food. Kim et al. (2009) has identified tourists' local food consumption model by using grounded theory, and proposed motivational factors, demographic factors, and physiological factors. Among those factors, motivational factors include exciting experience, escaping usual surroundings, health concern, learning knowledge, authentic experience, reunion, prestige and status, sensory experience, and surrounding atmosphere. Kim and Eves (2012) contend that excitement, escaping daily life, sensual entertainments, relaxation and health should be included in physical motivational factor. Based on the above findings, the paper adopts four motivational factors proposed by Fields (2002): physical, cultural, social and prestige dimension.

\subsection{Gastronomic Tourism}

Gastronomic tourism is playing an important role in changing our life. Modern life with high-speed pace makes people spend less time on cooking. In the meantime, eating out, and attending food festivals has become interesting activities (Hall et al., 2003: pp. 102-120). When people begin to pursue leisure experience related to food, gastronomic tourism has received the attention.

Gastronomic tourism is also known as food tourism or culinary tourism. Notion of culinary tourism was put forward and defined by Long (2004) as a global activity in which people participate in "other" food culture, including tasting, consumption, preparation and display food. Smith \& Xiao (2008) define culinary tourism standardization as a kind of touristic experience resulting from appreciation, and consumption of local food. The authors point out that seeking unique eating experience is the most motivational factor during vacation for some tourists. Wolf (2002) emphasized that gastronomic tourism motivated tourists to enjoy both food and unforgettable dining experience at the same time. To Hall et al. (2003: p. 308), food tourism is defined as a kind of tourism aimed to visit food producers, attend food festivals, and eat at restaurants. They all emphasized local food and food-related experience as the center of gastronomic tourism.

The paper mainly explores tourist food preferences and the motivation for food consumption. When local food becomes the major attraction for tourists, gastronomic tourism emerges. In a narrow sense, gastronomic tourism is a series of activities which features as local food and unique food culture to attract tourists to enjoy local food.

\section{Research Methodology}

The present research project mainly uses qualitative methods. Specifically, it includes in-depth interviews, observation, and informal conversation. The research is focused on tourists' views on food preferences and motivational factors for food consumption. Participants observations and in-depth interviews are employed for the study from December 5, 2013 to February 10, 2014.

Considering the practical difficulties in interviewing tourists of different regions in China, the study focused its attention on Chinese tourists who visited Shenzhen. Here are two reasons to choose the place as the interview location. Firstly, Shenzhen is an open and modern city. Many tourists go to Shenzhen for traveling. Secondly, Shenzhen cuisine provides Chinese tourists from different regions a chance to experience different foods that are different from their own tastes. Interviews were held in the Window of the World 世界之窗, Dongmen 东门老 街 of Shenzhen. And the small group interview (including 4 - 6 tourists) was adopted. A total of nine interviews were held with forty participants in the two interview locations.

\section{Research Findings}

\subsection{Food Preferences in Different Regions}

Through analysis of the recorded interviews, the study finds out that tourist food preferences among Chinese people vary in different regions. In Southwest of China such as Sichuan, Guizhou, and Guangxi Provinces, people prefer spicy food when they are traveling, the food preferences and habits remain unchanged. This finding further confirms that Chinese people are more willing to enjoy familiar taste. At the meantime, food preferences from different regions are more and more similar. Tourists on vacation like to try more novel and unfa- 
miliar food than before. The reasons are:

1) Improvement of people's living standard contributes to eating out more and more.

2) People have more opportunities to try local food during their vacation.

3) A number of establishments provide featured cuisines by adapting them to the taste of local people.

\subsection{Motivational Factor for Food Consumption}

When tourists go out for traveling, they often try the local foods of the places they visit. Group tourists may even require tour guides to arrange local dining activities. Local food plays an important role in touristic experience. But for some tourists, enjoying local food is the major motivation to travel, and they can experience a different culture from their own when they have a taste of local food. The present research finds that almost all the participants will take the bagged local food to their friends and relatives.

One interviewee, who was born and grew up in northeastern China, began the further study in Hubei Province in 2013. He said: "When I travel, I always focus on the local food first. If there are friends in local place, we will spend time enjoying local food together, but if not, I'll explore local food myself. More specifically, when I was in Guangzhou on vacation, I tried the pineapple bread, I chose sweet pasty in Hong Kong, I went to the hui street 回民街 in Xi'an City to taste all kinds of noodles.” The participate likes to experience local food and food culture, when traveling, and enjoys the pleasure of spending time with friends tasting local food.

\subsection{Gastronomic Tourism}

The study shows that most of the participants like to taste local food during their trip. Only a few of tourists would like to travel for food festivals or other food-related activities. The finding shows that most Chinese tourists treat local food as an extension to their daily dietary experience. Here, local food comes out as a supporting experience (Quan Shuai \& Wang Ning, 2004). However, some tourists go to a food festival instead of fabulous sightseeing, and then local food turns to be a peak experience. Trauer (2006) regards the purpose or motivation for traveling as a standard to decide if a certain kind of tourism was a special interest tourism. According to the comment, when tasting local food or attending food festivals is seen as the major motivational factor for a trip, the trip can be seen as gastronomic tourism.

\section{Conclusion}

With the development of destination market in China, local food plays a more and more important role in touristic experience. Tourists quest for both various food and spiritual satisfaction. On one hand, the destination marketer should adapt the local food to cater tourists' tastes and preferences. On the other hand, the destination should concentrate on the preservation of local specialties and food culture. In addition, food festivals with their themes based on interesting local stories and legends should be held. With all the endeavors, destination marketer will not only promote their own food culture, but also enrich food-related activities to enhance the image and the appeal of the destination.

\section{References}

Chang, K. C. (1977). Food in Chinese Culture: Anthropological and Historical Perspectives. New Haven: Yale University Press.

Chang, R. C. Y., Kivela, J., \& Mak, A. H. N. (2010). Food Preferences of Chinese Tourists. Annals of Tourism Research, 4, 989-1011. http://dx.doi.org/10.1016/j.annals.2010.03.007

Chun Juan 陈涓 (2003). Dili huanjing dui woguo yinshi wenhua de yingxiang 地理环境对我国饮食文化的影响 [Effects of the Geographical Environment on Chinese Food Culture]. Fujian Jiaoyu Xueyuan Xuebao, 4, 62-63.

Cohen, E., \& Avieli, N. (2004). Food in Tourism: Attraction and Impediment. Annals of Tourism Research, 4, 755-778. http://dx.doi.org/10.1016/j.annals.2010.03.007

Enteleca Research Consultancy (2000). Tourist's Attitudes towards Regional and Local Food. The Ministry of Agriculture, Fisheries and Food, and The Countryside Agency by Enteleca Research and Consultancy Ltd.

Fields, K. (2002). Demand for the Gastronomic Tourism Product: Motivational Factors. Tourism and Gastronomic. London and New York: Routledge.

Fischler, C. (1988). Food, Self and Identity. Social Science Information, 27, 275-292. 
http://dx.doi.org/10.1177/053901888027002005

Hall, C. M., et al. (2003). Food Tourism around the World: Development, Management and Markets. Oxford: ButterworthHeinemann.

Hjalager, A., \& Richards, G. (2002). Tourism and Gastronomic. London: Routledge.

Kim, Y., Eves, A., \& Scarles, C. (2009). Building a Model of Local Food Consumption on Trips and Holidays: A Grounded Theory Approach. International Journal of Hospitality Management, 3, 423-431. http://dx.doi.org/10.1016/j.ijhm.2008.11.005

Kim, Y., \& Eves, A. (2012). Construction and Validation of a Scale to Measure Tourist Motivation to Consume Local Food. Tourism Management, 33, 1458-1467. http://dx.doi.org/10.1016/j.tourman.2012.01.015

Kim, Y. H., Kim, M., \& Goh, B. K. (2011). An Examination of Food Tourist’s Behavior: Using the Modified Theory of Reasoned Action. Tourism Management, 32, 1159-1165. http://dx.doi.org/10.1016/j.tourman.2010.10.006

Long, L. (2004). Culinary Tourism (Material Worlds). Lexington, KY: The University Press of Kentucky.

Longue, A. W. (1991). The Psychology of Eating and Drinking: An Introduction. New York: WH Freeman.

Okumus, B., Okumus, F., \& McKercher, B. (2007). Incorporating Local and International Cuisines in the Marketing of Tourism Destinations: The Cases of Hong Kong and Turkey. Tourism Management, 28, 253-261. http://dx.doi.org/10.1016/j.tourman.2005.12.020

Quan Shuai, \& Wang Ning (2004). Towards a Structural Model of the Tourist Experience: An Illustration from Food Experience in Tourism. Tourism Management, 25, 297-305. http://dx.doi.org/10.1016/S0261-5177(03)00130-4

Rozin, E., \& Rozin, P. (1981). Culinary Themes and Variations. Natural History, 90, 6-14.

Rozin, P. (1996). The Socio-Cultural Context of Eating and Food Choice. New York: Blackie Academic and Professional.

Smith, S. L. J., \& Xiao, H. G. (2008). Culinary Tourism Supply Chains: A Preliminary Examination. Journal of Travel Research, 46, 289-299. http://dx.doi.org/10.1177/0047287506303981

Trauer, B. (2006). Conceptualizing Special Interest Tourism-Frameworks for Analysis. Tourism Management, 27, 183-200. http://dx.doi.org/10.1016/j.tourman.2004.10.004

Wolf, E. (2002). Culinary Tourism: A Tasty Economic Proposition. 